This item was submitted to Loughborough's Research Repository by the author.

Items in Figshare are protected by copyright, with all rights reserved, unless otherwise indicated.

\title{
Paralympic legacy: exploring the impact of the Games on the perceptions of young people with disabilities
}

\section{PLEASE CITE THE PUBLISHED VERSION}

http://dx.doi.org/10.1123/APAQ.2014-0237

\section{PUBLISHER}

(c) Human Kinetics

\section{VERSION}

AM (Accepted Manuscript)

\section{PUBLISHER STATEMENT}

This work is made available according to the conditions of the Creative Commons Attribution-NonCommercialNoDerivatives 4.0 International (CC BY-NC-ND 4.0) licence. Full details of this licence are available at: https://creativecommons.org/licenses/by-nc-nd/4.0/

\section{LICENCE}

CC BY-NC-ND 4.0

\section{REPOSITORY RECORD}

Coates, Janine, and Philip Vickerman. 2019. "Paralympic Legacy: Exploring the Impact of the Games on the Perceptions of Young People with Disabilities". figshare. https://hdl.handle.net/2134/22546. 
AS ACCEPTED FOR PUBLICATION

2

3

4

5

6

7

8

9

10

11

12

13

14

15

16

17

18 Nottingham Trent University

19 Division of Psychology

20 Burton Street

21 Nottingham

22 NG1 4BU

$23 \quad$ Janine.Coates@ntu.ac.uk

24 Tel: (0115) 8486122

\section{Corresponding Author:}

people with disabilities.

Janine Coates

Nottingham Trent University, Division of Psychology (UK)

Philip Vickerman

Liverpool John Moores University, School of Education, Health and Community (UK) 


\section{AS ACCEPTED FOR PUBLICATION}

\section{Abstract}

2

The London 2012 Olympic and Paralympic Games aimed to deliver a legacy to

3 citizens of the United Kingdom, which included inspiring a generation of young people to

4 participate in sport. This study aimed to understand the legacy of the Paralympic Games for

5 children with disabilities. Eight adolescents (11-16 years of age) with physical disabilities were

6 interviewed about their perceptions of the Paralympic Games. Thematic analysis found three

7 key themes which further our understanding about the Paralympic legacy. These were:

8 Paralympians as role models; changing perceptions of disability and the motivating nature of

9 the Paralympics. Findings demonstrate the Games were inspirational for children with

10 disabilities, improving their self-perceptions. This is discussed in relation to previous literature

11 and core recommendations are made.

13 Key words: Olympic Games, London 2012, role models, legacy, mega-events. 


\section{AS ACCEPTED FOR PUBLICATION}

\section{Introduction}

In summer 2012 London, United Kingdom (UK) hosted the Olympic and Paralympic Games. The British Olympic and Paralympic Associations won the bid to host the events based on the 2012 legacy Action Plan by the Department for Culture, Media \& Sport (DCMS) (2008), which set out five legacy promises. These included aims to develop the nations sporting prowess and inspire a generation of young people. Promises to 'inspire a generation’ intended to give "hundreds of thousands of young people across the UK opportunities to learn new skills, try different activities and enjoy being part of their communities as a result of the London 2012 Games” (DCMS, 2008:42). According to the bid, young people are at the heart of the legacy with plans to aid their development by creating cultural and sporting initiatives and providing young people with more opportunity to become involved in their communities. It is this promise to young people which stimulated interest in this research - to consider what the sporting legacy of the 2012 Paralympic Games is and its impact on young people with disabilities. This study explores the perceptions of young people with disabilities about the Paralympic Games and what, if any, impact The Games had on their attitude toward sport and disability. For the purpose of this paper, children and young people will be used interchangeably to refer to children up to the age of 16, unless otherwise stated.

Research exploring children with disabilities' perceptions of the Games is scarce. Much Olympic research tends to focus on doping (Fitch, 2012), elite athlete health (Kippelen, Fitch, Anderson, Bougault, Boulet, Rundell, et al, 2012), performance (Hollings, Hopkins, \& Hume, 2012), economic factors (Shibli, Gratton, \& Bingham, 2012), and cultural development (Graham, Gilbert, Minton, Perryman, Poynter \& Westall, 2013), yet few consider the impact of these events on children and young people. In fact, a literature search revealed just a handful of recent papers which have specifically considered children and young people in relation to the Olympic / Paralympic Games and 'Olympism' (Armour \& 


\section{AS ACCEPTED FOR PUBLICATION}

1 Dagkas, 2012; Chatziefstathiou, 2012; Ferrara, Burns \& Mills 2015; Fitzgerald, 2012;

2 Lenskyj, 2012; Broderick, 2013) much of which focuses on the philosophical and pedagogical

3 values of educating children on Olympic values. However, little to no research has considered

4 the impact of the Olympic and Paralympic Games on the perceptions of children. Indeed,

5 Weed, Coren, Fiore, Wellard, Mansfield, Chatziefstathiou et al. (2012) indicate there is no

6 published evidence to suggest the Olympic and Paralympic Games increase public sport

7 participation, although admit that this is not suggestive of the Games having no impact on participation, but rather arguing it highlights the dearth of research in this area. To date, no published empirical studies exploring children with disabilities views on these 'mega-events' (Armour \& Dagkas, 2012) have surfaced, and Dickson, Benson and Blackman (2011) indicate a general lack of research regarding Paralympic legacy. This kind of research might shed light on the legacy and develop an understanding whether these events motivate this marginalised group of young people to take part in sport. Indeed, Misener, Darcy, Legg and Gilbert (2013) show that, with the exception of one study (Greig, August \& Race, 2006) there are no empirical studies which demonstrate increased participation in sport.

Despite the lack of published evidence, the English Federation for Disability Sport (EFDS) (2012) did produce a report of survey findings relating to the impact of the Olympic and Paralympic Games on people with and without disabilities. Completed by 521 individuals in England, UK - 17\% of whom had disabilities - the report gives some preliminary findings about the change in attitude toward disability sport created by the 2012 Paralympic Games. Overall, it was found that perception change was positive - individuals who watched the Paralympic Games reported greater demand for media coverage of disability sport, and 80\% of participants with disabilities stated they would consider taking part in more sport after watching the Games. Despite this, $90 \%$ of sports clubs who participated indicated no change in the number of people with disabilities joining their clubs, with similar findings from the 


\section{AS ACCEPTED FOR PUBLICATION}

1 Sport and Recreation Alliance (2012). Therefore, it is possible that this change in perception

2 does not necessarily result in increased sports participation amongst individuals with disabilities. Alternatively, as this report was produced only two months following the Paralympics Games, it could be that any increase in sport engagement will be seen more gradually over a longer period of time. Indeed, according to the Centre for Sport, Physical Education and Activity Research (2012), no previous Games have raised participation levels in sport. They note this is for two reasons, firstly, no previous games have set out specifically to raise participation levels and, secondly, there has been no systematic literature to measure increase in participation rates.

Nevertheless, the report does highlight some salient points which have been raised by previous literature pertaining to children with disabilities. Firstly, it indicates media coverage of disability sport can have an impact on perceptions of disability. The 2012 Paralympic Games was the first to see mass media coverage, particularly in the UK. In previous Games, there was little to no media coverage of athletes with disabilities, particularly on television; and generally individuals with disabilities in the media are often portrayed negatively (Brittain, 2004a). This is supported by Hardin, Hardin, Lynn and Walsdorf (2001) who indicate media representations of disability contribute to the development of negative stereotypes, yet some forms of media can produce positive impacts. In particular, they note that coverage of disability sports could lead to positive attitudes about disability. This is supported by Brittain's (2004a) research, in which he interviewed a number of Paralympic athletes. One participant, Ian, sees media coverage of disability sport as important in attitude change about disability, stating "Unless they can actually see more disabled people being successful in various roles, then it's hard to get it across that disabled people are just as able and equal to able-bodied people” (p 446). Additionally, Misener, Darcy, Legg and Gilbert (2013) indicate previous studies have demonstrated a negative impact on perceptions towards 


\section{AS ACCEPTED FOR PUBLICATION}

1

disability as a result of the Paralympic Games, through the reinforcement of the 'supercrip’ stereotype. Despite this, Gold and Gold (2007) argue the Paralympic Games have been instrumental in changing attitudes towards disability and have "accelerated the agenda for inclusion” (pp. 133). This highlights the role the Paralympic Games might have in changing attitudes about disability - whether that is positive or negative attitude change. However, Fitzgerald (2012) argues caution should be taken in focusing on disability events to promote engagement. She continues suggesting we should look beyond traditional disability sport events to encourage children with disabilities to participate.

Research by Panagiotou, Evaggelinou, Doulkeridou, Mouratidou and Koidou (2011) further supports this. They showed a simulation-based Paralympic Sport Day programme prompted positive attitude change towards disability in children without disabilities aged 11 to 12 years. This provides some backing to the findings from the EFDS (2012) about potential positive perception change as a result of Paralympic Games, particularly given the increased coverage of the event in the UK, and the Olympic / Paralympic school sports days held in the run up to the Games. It is worth noting, however, that by using an active simulation-based sports day model it may have prompted more positive change through engagement in activities. Passive engagement through media coverage alone may have less impact. We should also recognise that increased awareness of disability could lead to reinforced notions of personal tragedy rather than empowerment (Kama, 2004; Misener, Darcy, Legg \& Gilbert, 2013).

Nevertheless, increased media coverage of disability sport could also create role models for children with disabilities. Role models have been written about extensively within psychological literature (e.g. see the work of Penelope Lockwood \& colleagues). Much of this work is built on social learning theory (Bandura, 1986), which posits the more relevant and similar a role model is to the observer, the more likely they are to effect behaviour / attitude 


\section{AS ACCEPTED FOR PUBLICATION}

1 change in the observer (Lockwood \& Kunda, 1997). Literature suggests that sports stars are

2 less likely to be considered role models than family members, friends and other entertainers

3 (Anderson \& Cavallaro, 2002). However, research by Vescio, Wilde and Crosswhite (2005)

4 shows that when a sports star is selected as a role model, this is influenced by their similarity

5 to the individual. In this study exploring female adolescents sporting role models, the role

6 models were either also female, shared the same heritage, or had similar sporting backgrounds

7 to the participants. While this research is specific to female adolescents who do not have disabilities it might give some insight into the potential of Paralympic athletes to act as role models for children and young people with disabilities, given the otherwise negative portrayal of individuals with disabilities in the media (Brittain, 2004a).

Related to this, the Paralympic Games might have some impact on children and young people with disabilities motivation to participate in sport. Indeed, Nind, Flewitt and Pavler (2010) suggest having positive role models for people with disabilities can have a positive impact. Furthermore, self-determination theory (Deci \& Ryan, 2002) has been used in sport psychology to understand individual motivation to participate in sport. It argues on the one hand, that sports participation is motivated by self-efficacy beliefs (Feltz, 1992). Selfefficacy, or the belief in ones abilities and capacity to enact a specific behaviour (Bandura, 1986) can be developed through social cues, including the media. For example, Di Lorenzo, Stucky-Ropp, Vander Wal and Gotham (1998) found interest in media sport was an important predictor of physical activity, particularly for boys. Similarly, Cavill and Bauman (2004), reviewed literature investigating the role of mass media in promoting physical activity and suggested mass media campaigns might have a place in improving self-efficacy. Although, they argue while the media might increase awareness of physical activity benefits, there is little evidence to suggest it brings about a change in behaviour. Taking this into account, it is 


\section{AS ACCEPTED FOR PUBLICATION}

1 possible viewing the Paralympic Games might have some effect on children with disabilities

2 perceptions of their own abilities but might not lead to children engaging in sport.

Indeed, Deci and Ryan (2002) argue self-efficacy (otherwise referred to as 'competence') alone is not enough to motivate sports participation. They state individuals require autonomy, competence (self-efficacy) and relatedness in sport to be motivated to participate. Autonomy refers to the individual's opportunity to freely choose the activity they participate in, and relatedness refers to a person's feeling of shared experience and belongingness. Given this, it is unlikely improved self-efficacy from viewing Paralympic sports or having Paralympians as role models will result in increased engagement in sport activity. Only when coupled with improved opportunity to engage in sport, might we see increased sport engagement among children with disabilities in the wake of the Paralympic Games. Indeed, research has shown children with disabilities participate in a narrower range of sport and physical activity compared with their non-disabled peers and report feeling excluded and different from others in relation to participation in school physical education (PE) (Blinde \& McCallister, 1998; Sport England, 2001; Goodwin \& Watkinsion, 2000; Fitzgerald, 2005). It is evident from this literature there are limited opportunities for children with disabilities to engage in sport. Although the legacy of the Games intended to improve participation in sport,, Sport England (2015) have shown year on year decreases in the number of people with disabilities participating in sport since the Games. This might indicate that more work needs to be done to improve participation in sport for individuals with disabilities.

Limited opportunity, or poor awareness about opportunities to engage in sport will restrict the motivation of children and young people with disabilities to participate in sport (Deci and Ryan, 2002). However, it is difficult to draw conclusions about the Paralympic legacy for young people without consulting with children with disabilities to understand their 


\section{AS ACCEPTED FOR PUBLICATION}

1 views about the Games. Therefore, this study aims to explore children with disabilities

2 perceptions of the Paralympic Games and disability sport in order to understand what impact,

3 if any, this event had on their attitudes towards participation in sport.

\section{Method}

\section{$5 \quad$ Research design}

A qualitative exploratory research design, using semi-structured one-to-one interviews (Robson, 2006) was employed for this research. Previous literature relating to children with disabilities and sport (e.g. Goodwin \& Watkinson, 2000; Fitzgerald, 2005; Coates, 2011, Jobling, 2012) suggested qualitative designs work well for research aiming to understand the perceptions of this population. Indeed, a review paper by Coates and Vickerman (2013) recommends flexible qualitative designs for use with children with disabilities, indicating that while quantitative designs might yield more generalizable data, they do not serve to understand children's perceptions and attitudes towards sport and physical activity. They further suggest qualitative designs are often more appropriate as they offer flexibility in data collection and analysis to respond to the specific communication needs of people with disabilities.

A 7 item interview schedule (See Table 1) was developed to explore the perceptions children with disabilities have regarding the Paralympic Games, sport for people with disabilities more generally, and personal perceptions of sport and physical activity. Questions asked were broad and open, allowing the child to explore their perceptions and the researcher to direct conversation based on what each child said in order to generate rich data. Moreover, Cresswell (2007) suggest this type of 'thick data' gathering offers more opportunity for trustworthiness and transferability of the data. Additionally, children were given the opportunity to watch a short video of some Paralympic sports, including sitting volleyball, 


\section{AS ACCEPTED FOR PUBLICATION}

1 wheelchair basketball, swimming and athletics, as a prompt, as interviews took place between

2 the October and February following the 2012 Games. This also provided participants with examples to reflect upon. Interviews took place at the child's school in a quiet room away from peers and teachers to reduce any influence these people might have on the child's responses (Scott, 2000). Interviews were conducted by the first author and were audio recorded.

\section{[INSERT TABLE 1]}

\section{Participants}

Eight children in two schools in the East Midlands, UK (due to ease of access for the researchers) took part in this study. Schools were one mainstream secondary school which included a unit for children with physical disabilities and one special school (separate disability and non-integrated school) catering for children with a range of disabilities. Children between the ages of 11 and 16 with physical and / or sensory disabilities were invited to participate in the study. The rationale for selecting this age range was due to a greater likelihood of children having watched the Paralympics and being able to comment upon them. Physical disability, for the purpose of recruitment, included children who had difficulty with fine and /or gross motor functioning (but not requiring mobility assistance) as well as them requiring mobility assistance (wheelchairs) in their day-to-day functioning. Sensory disability included those with visual and / or auditory dysfunction which impacts on their day-to-day functioning. Ten children per school were invited to participate. While there were more children with disabilities who could have been invited to participate, the liaison in each school felt more comfortable inviting a small number of selected children, and felt this would cause the least disruption. Decisions about who to invite were made by the school head teacher in the special school, who selected those children meeting selection criteria who were more able to communicate verbally. In the mainstream school, potential participants 


\section{AS ACCEPTED FOR PUBLICATION}

1

were selected by the school's adapted PE liaison, and included children meeting the age and disability criteria, whom the liaison felt would be more willing to participate. Whilst the sampling was not ideal, both the head teacher and mainstream school liaison were encouraged to invite a broad range of children to reduce bias, however it is acknowledged sampling in this way is likely to introduce some selection bias. Nevertheless, letters and consent forms were sent out to parents to inform them of the research and both parents and the child themselves provided written consent to participate. Participation in the research was voluntary.

A total of eight children took part in the research including three from the special school and five from the mainstream school (40\% response rate). Five participants were male and three were female. The mean age of the children was 14.6 years ( $s d=1.65)$. All participants were classified as having physical disability and no children with sensory impairment took part in the study. All children attending the special school, and David in the mainstream school had associated intellectual disability. All participants except for Cassie used wheelchairs. Table 2 provides more details relating to the individual participants (please note, pseudonyms are used for anonymity).

\section{[INSERT TABLE 2]}

Full ethical approval was received from Nottingham Trent University School of Social Sciences ethics board and research was conducted in line with both British Psychological Society ethical guidelines and British Educational Research Association (BERA) research ethics guidelines. All participants and their parents gave informed consent to take part and participants were made aware of their right to withdraw at any point during the study.

\section{Data analysis}

Thematic analysis was employed using the Braun-Clarke approach (Braun \& Clarke, 2006). This method for thematic analysis incorporates 5 stages and is set out below: 


\section{AS ACCEPTED FOR PUBLICATION}

1. Familiarisation with the data. Interviews were transcribed verbatim, read and re-read. Initial descriptions of the data were noted.

2. Generating initial codes. Interesting features in the data were highlighted and coded systematically across transcripts, drawing out key ideas put forward by participants. For example, where children discussed positive affect towards the Games, codes were generated to indicate the reasons for this, and / or the effect of this on the child and their perceptions of themselves, others or sport more generally. Examples of codes generated during this stage included "positive affect - increased motivation to take part in sport” and “change in self-perception - perceived as equal”.

3. Searching for themes. Codes were collated and organised into relevant themes. At this point, several possible themes were identified, and those with significant overlap with other themes were grouped.

4. Reviewing the themes. Themes were reviewed according to their 'fit' with the coded data and the data set as a whole. In addition, at this stage, credibility of the coding and themes was checked (Lyons \& Coyle, 2007). Two independent reviewers (postgraduate child psychology students) reviewed the coded data which was checked against the analysis undertaken by the lead author for consistency. This method of inter-coding analysis has the advantage of reducing error and bias in coding (Cresswell, 2007). Initial themes were then sent to the second author for review.

5. Defining and naming themes. Themes were refined and defined to encapsulate the messages from the coding in an organised and coherent fashion. Four themes were identified, including the three reported in this paper and one additional theme - "PE facilitating engagement in physical activity”. During the review process, it was determined that the fourth theme did not fit with the aims of this paper, and as a result has not been reported. 
AS ACCEPTED FOR PUBLICATION

1

2

3

4

5

6

7

\section{Results}

The thematic analysis revealed three themes relvant to the aims of the study:

- Paralympians as role models

- Changing perceptions of disability

- The motivating nature of the Paralympics

A description of each theme follows.

\section{Paralympians as role models:}

From the interviews it was evident the Paralympic Games were perceived positively by all participants, with many describing them as "good”, “exciting” and “cool”. Participants experienced the Paralympics through a range of mediums including television, radio and newspapers, and a small number in the special school had been to London to watch some of the athletic events live. Further probing of the reasons behind these descriptions elucidated that children had understood the purpose of the Paralympic Games and what this meant to them. Children explained the Paralympic Games were equivalent to the Olympic Games, but were specifically targeted at athletes with disabilities:

Georgina: “It's an Olympic version for disabled people... just so they're involved just like other people are with the Olympics.”

Simon: "They are like, people in wheelchairs or disabilities or like in the Olympics but it's called the Paralympic because they can't do the stuff what the Olympic people do.”

Chris: "Olympians that do Paralympics... because they're in wheelchairs." 


\section{AS ACCEPTED FOR PUBLICATION}

These participants indicate there is a significant difference between the Paralympians and Olympians, and Simon suggests this might be due to the athletes' abilities. While Simon suggests Paralympians cannot do the same sports as Olympic athletes, later in his interview he discusses preferring the Paralympic Games as it was less boring and contained more action. Other participants agreed they preferred watching the Paralympic Games and with the exception of Simon, did not suggest the Paralympic athletes were less able than Olympians. In fact, the differences between Paralympic and Olympic athletes seemed to be a source of inspiration, as Zara, Simon and Georgina go on to explain when asked to clarify this difference:

Zara: “It's quite interesting watching it [Paralympics] and it's quite amazing how people do. (Interviewer: You said that you find it quite amazing what people can do. What do you mean by that?) Like how, it's like you see disabled people and then you see normal people but it shows that you can achieve a lot even if they are disabled."

Simon: "Um, running. They have like metal legs and they can run just as fast so it's kind of better than the Olympics... they have disabilities and they think "I don't care about this, I am gonna do it”. And they do it. But it's amazing!”

Georgina: “They're very inspirational, just how they don't let anything stop them.”

Feeling inspired by the Paralympic athletes was evident in all transcripts and participants made clear it was the strong mental and physical characteristics of the athletes themselves which led them to feel this way. Children highlighted that the athletes had physical strength and prowess to be successful in their chosen sports, had motivation and will to train hard to achieve Paralympic success, and also had the mental strength to overcome adversity in order to succeed. Early in the interviews, many of the children focused on the skill and talent demonstrated by the Paralympic athletes. 


\section{AS ACCEPTED FOR PUBLICATION}

Zara: "They're strong players... because they like, believe in themselves and have strength to go out there and show their skills."

Warren: “He’s [Richard Whitehead - Para-athlete and 2012 Paralympic gold medallist] very good at what he does."

Chris: “They're [Paralympians] good because they have to train long and hard and they have to do lots of fitness to take part because the Paralympics is a lot harder than what the Olympics is.” [Interviewer: "Why do you think it's harder?”] "Well, no, they're both the same, but with the Paralympics, with people that are blind, it's a lot harder [because of] not being able to see."

Particularly evident from this was the role model-effect Paralympians appeared to have on the participants, characterised by their ability to challenge adversity in order to succeed. This was specifically in terms of the athlete's disabilities, and was a feature of the athlete's character which prompted some participants to recognise their own disability should not hold them back, suggesting participants might have an improved self-efficacy. The participants felt relatedness (Deci and Ryan, 2002) to the Paralympic athletes, in terms of sharing in the challenges of disability, and viewed their success as an achievement not only for the athletes, but for people with disabilities more generally. This did not seem to be relevant only to sporting success, but was considered more broadly. Zara in particular considered this and how the Paralympic Games made her appreciate her own potential more generally:

Zara: “Zara: “They're [Paralympic and Olympic athletes] both good, but I'd say the Paralympics are more good as they're disabled and they're different...they're all the same and they can all achieve." 


\section{AS ACCEPTED FOR PUBLICATION}

Reflecting on disability and the success of Paralympic athletes also led participants to consider the effect the Paralympic Games had on the way they viewed themselves as individuals with disabilities. Many participants were able to recognise the similarities they shared with Paralympians in terms of disability, often reflecting on how they also used wheelchairs and using phrases such as "like me”, for example:

David: "Paralympic games [athletes are] in a wheel chair, like me"

In particular, watching the Paralympic Games seemed to lead participants to consider their own self-efficacy and self-determination (Deci and Ryan 2002). In response to a question "How do you feel after watching the Paralympics", some reported feeling more confident in themselves since watching the Paralympics. Zara and Chris sum this up:

Zara: "Because you look at them [Paralympic athletes] and you look at yourself and then you see the similarities, like and that you have legs but they don't, and it makes you think there's a difference between them but if they can do it, you can do it and it makes you want to do it as well... It's [helped me] in a good way. It's been helping me, like it's even in school that's changed me, but I'm able to work by myself, I'm able to go out there and do stuff. It's made me feel stronger, more confident."

Chris: "I like the people that are in it [the Paralympics], the athletes because I like to see what athletes are racing, what they're doing. [Interviewer: Why's that?] Because I like to watch what the athletes are doing because it gives me an idea of what I can do, what I'd want to do.”

\section{Changing perceptions of disability}

Participants frequently considered the role the Paralympic Games had in changing public perception about disability. They had a firm belief the Games had a positive effect on people's perceptions, leading them to view individuals with disabilities in a more positive 


\section{AS ACCEPTED FOR PUBLICATION}

1 light. While exploring opportunities for individuals with disabilities to participate in sport,

2 Zara reflected upon how the Paralympic games might change perceptions of sport: Zara: Now [since the Paralympics] people are, like with the Paralympics, it shows other people who are watching that even though they're disabled they can still achieve and stuff ... and so now they understand and treat you properly. It's made people aware that they can do sports.

While the children interviewed did not increase their sporting activity in light of the Games they felt that the Paralympics played an important role in changing their personal views of disability. It was evident from the data in response to the question, "what do you think of the Paralympic athletes and what they have achieved?" that the participants undoubtedly felt that the Paralympic Games depicted the athletes as exceeding expectation. This is highlighted in the following quotes:

Cassie: "I think it's [Paralympics] actually fantastic because say the people who has got the disability problems that take part in things that they can do!"

Zara: "You see disabled people and then you see normal people but it shows that you can achieve a lot even if you are disabled... Like winning. Like when they actually won. It shows that they [disabled athletes] can achieve and stuff.”

Simon: “They have disabilities and they think, “I don't care about this, I'm going to do it”. And they do it, but it's amazing!”

This highlights not only that the Paralympics might play a role in changing perceptions about disability. These quotes show participants were in many ways in awe of the athletes' performance in the Paralympic Games but it also led several children to think reflect on their own abilities.

This is considered in more detail in the next theme. 


\section{AS ACCEPTED FOR PUBLICATION}

\section{The motivating nature of the Paralympics}

Findings showed participants perceived the Paralympic Games as a tool for motivating individuals with disabilities to do more sport. Participants noted that the general feel good factor and people discussing the games made them feel more motivated to get involved in the future. Although none of the children interviewed had taken up more sport as a result of the Games, they felt more confident should they wish to do so. There was a general feeling of optimism that the Paralympic Games would open up new opportunities for individuals to do sport as well as encourage people with disabilities to consider taking advantage of these opportunities, as demonstrated below:

Chris: "I think they'll [people with disabilities] be able to get sport."[Interviewer: Do you think the Paralympics encourages people to take part in sport?] "Yes. I don't know why that is, but it does encourage them to take part."

Cassie: "It gets them [people with disabilities] a good chance that they can do it [sport] or not do it... just like a bigger like opportunity that they can do it if they want to.”

[Interviewer: Did you do a lot of sport before the Paralympic Games?] Simon: "Um, only those two, tennis and badminton, but now I want to join more clubs.”

However, while it was perceived that the Paralympic Games might increase opportunity for sport engagement, Simon's perceptions echoed that from the literature mentioned above. He indicated that while there are benefits to inclusive physical activity, there are also barriers preventing children with disabilities from participation.

Simon: [I find sport fun] with like, other people. With other people who have like no disability as well as other people who have disabilities is quite fun... I prefer it when with everyone else”... 


\section{AS ACCEPTED FOR PUBLICATION}

Interviewer: "Do you think there's enough opportunity out there for them [people with disabilities] to go and do sports?”

Simon: "No... there could be more gyms for wheelchair people and like more badminton and that ... I don't think it's fair [to have more clubs for people without disabilities]. Just because you can like do stuff what other people can't, so like the wheelchair user or a person who can walk, they should both have the same stuff."

Simon points out a key frustration which might be shared by other individuals who have disabilities - the lack of spaces or opportunities for disability sport in the community (Smith \& Thomas 2006) and the feeling of being marginalised because of disability. In fact, several children indicated that there was lack of opportunity for them to engage in sport outside of school, or demonstrated little awareness of any opportunities which did exist. Barriers to engagement in physical activity demotivate children from participation in extracurricular sporting activities. Deci and Ryan (2002) argue that motivation for sport participation incorporates the need for autonomy, which in this case awareness of opportunities for sport participation. If this is lacking, motivation to participate will dip. Nevertheless, children in this study believed the Paralympics would encourage more children with disabilities to do sport, prompting a need for "the council" to finance these spaces, and improve advertising, such as putting posters advertising relevant clubs on the school gate. Additionally, Simon's statement that he would now like to join more sports clubs shows there is an increasing need for disability-specific or disability friendly sports opportunities for children in the community. This might indicate increased motivation to participate in sport, hence the desire for more opportunity.

When asked the question "have you taken part in any sports activities outside school?" only two participants had taken part in formal sporting activity outside of school. Simon had 


\section{AS ACCEPTED FOR PUBLICATION}

1 previously been part of a badminton club, although left as there was only one other person

2 with a disability at the club. He explains:

Simon: "Badminton was not very much people, that there was only me and another guy in a wheelchair." [Interviewer: So could you do it with other people who weren't in wheelchairs?] "Yeah, we did it once with someone who could walk but then they went out [left the club]. [Interviewer: Would you want to go back?] "No, not really."

Cassie on the other hand, who was the only participant not requiring a wheelchair, has been successful in athletics, taking part at a national level and placing $8^{\text {th }}$ in the country.

Cassie: "I came in $8^{\text {th }}$ place in the country...Actually I found it actually fantastic! I've been told by my head teacher that I'll get involved in the assembly like from my tutor group and I got a medal and everything!”

Promoting sporting opportunities for individuals with disabilities in the wake of the Paralympic Games (and the 2014 Commonwealth Games) might prove beneficial to children. Further, ensuring children with disabilities can make the most of these opportunities may also improve participation and perceptions of sport outside of school. Simon's experience appears to be one of inclusion, where he was given opportunity to participate with children without disabilities; however for him this had not been successful. As a result he felt that there needed to be more opportunities for people with disabilities to become involved in sport. Cassie on the other hand had partaken in activities specific to her needs, so her experience was more positive, which indicates that when children's needs are met, their attitudes toward sport improve.

This is further emphasised by the experiences of Georgina, who had been unable to take part in any physical activity due to her medical condition. When asked "has your disability hindered participation for you?” Georgina noted how she was greatly 


\section{AS ACCEPTED FOR PUBLICATION}

1

disempowered by the inability to participate with her friends and make decisions about her own physical activity. This is demonstrated below:

Georgina: "I don't join in any of the [PE] lessons because of my condition. [I'd like] just being a part of it... I feel left out. [Interviewer: Is not taking part something that's been decided for you or a choice you've made?] "It's been decided for me by my doctors. [I'd like to be involved] even if it's just on the side lines at least I'm involved if not completely involved [but can't] not unless the doctors say otherwise"

[Interviewer: Do you think it's good to have sport for people who have disabilities?] "Yeah, just so they're not feeling left out and worthless. Just something that you can do and they can set themselves goals and not feel down."

It is evident from this that Georgina feels disempowered with regard to taking part in sport. The decisions made are not hers and she feels unable to change this without the go ahead from her doctors. However, she acknowledges that sport can be motivating, allowing individuals to set goals and achieve. This is something Georgina did not feel was within her reach yet. She believed that, the opportunity to at least attend lessons and be included, would have made her feel better. This consolidates the importance of sport and physical activity engagement for children and young people as a natural part of their development. Based on Georgina's experience, it is evident that sport has the potential to empower and cultivate selfdetermination which can have a significant impact on the life experiences of young people.

\section{Discussion}

This study supports previous limited research to date and highlights three key outcomes related to the Paralympic Games. Firstly, it shows Paralympians can be perceived 


\section{AS ACCEPTED FOR PUBLICATION}

1

as role models to children with disabilities and this supports wider psychological research on role models, and demonstrates children with disabilities are able to relate to the similarities between themselves and Paralympic athletes (Deci and Ryan, 2002; Vescio, Wilde, \& Crosswhite, 2005). Indeed, children acknowledged the athletes sporting prowess, however, their positive perceptions of athletes went beyond this, allowing children to identify with another person who has a disability and has been successful. It appears this relatedness to the Paralympians' disabilities provides children with the opportunity to reflect on their own disabilities and to view these more positively.

This view supports current literature relating to role models. Firstly, it supports the work of Lockwood and Kunda (1997) who posit a superstar will only become a source of inspiration to individuals if they are deemed to be relevant to them personally. In this study, Paralympians were relevant to children because they shared a core commonality - disability. Lockwood and Kunda (1997) also state that the superstar's demonstrated abilities should be attainable in some way to the individual in order to inspire them. For most children in this study, sporting success was not necessarily an attainable or desired aim for them, yet the success of the Paralympians was attainable to children as it showed them that they too could succeed in their individual goals, just as disability had not restricted the ability of the Paralympians to achieve their goals. Thus, the Paralympic Games become a tool for empowering children with disabilities.

Research by Purdue and Howe (2012) support the view Paralympians can act as sporting role models, although they claim its effect does not extend as far as empowering individuals who are not Paralympians themselves. However, this research was carried out with adults who were identified as being Paralympic Stakeholders. As such, their findings may not be applicable to children with disabilities where the influence of a role model might have a more profound, empowering effect. Equally, the findings from this study challenge 


\section{AS ACCEPTED FOR PUBLICATION}

1

studies by Goggin and Newell, (2000) Jobling (2012) and Misener, Darcy, Legg, and Gilbert (2013) which suggest the Paralympic Games reinforce disability stereotypes, representing Paralympic athletes as ‘supercrips’ (heroic athletes who overcome their disability).

Whilst the children in this study did perceive the athletes as achieving in spite of their disability, this tended to be considered as a positive step forward in changing perceptions about disability, rather than reinforcing negative stereotypes. While few studies appear to exist in relation to the media coverage surrounding the 2012 Paralympic Games and its potential impact on public perception of disability, particularly that of children, given the increased airtime it received (particularly in the UK), it is possible the Games may have led to some change in public perception. It is also possible, given that previous research tends to focus on adult perceptions, that the results from this study challenge previous literature simply because children perceive the Games and their effect differently.

In understanding the relationship between role models and motivation (Lockwood \& Kunda, 1999), this research also showed the ability to relate to the Paralympic athletes led to positive changes in children's perception of themselves, thus enhancing confidence in their own abilities. This, again, was not limited to sport. Rather, it demonstrated the power of positive role models with disabilities in improving children's perceived self-efficacy and motivation to succeed. Indeed, participants' experiences of sport and physical activity prior to the Paralympic Games were varied. Lockwood, Sadler, Fryman and Tuck (2004) argue for example that a positive role model (an individual who has achieved a high level of success) can encourage others to pursue similar accomplishments.

While this literature does not relate directly to the experiences of children with disabilities and the influence positive role models might have on their self-perceptions and behaviour, it does provide some insight into the possible impact Paralympic athletes might have on these children. It also highlights the need for positive media representations of 


\section{AS ACCEPTED FOR PUBLICATION}

1 individuals with disabilities, given the role the mass media has in assisting children's self-

2 efficacy development (Cavill \& Bauman, 2004). This would promote potential role models

3 for children, enhancing the positive impact it has. In addition to this, understanding the impact

4 of positive role models with disabilities on the perceptions and self-efficacy of children with

5 disabilities should also be further investigated to better understand any potential benefits, or

6 drawbacks for this under-researched population.

Children in this study felt more confident conceptually about participating in sport (competence), and had a greater sense of belongingness within the sporting community (relatedness), the lack of opportunity to do sport (or the lack of knowledge about existing opportunities) (autonomy) diminished the child's motivation to do more sport. This goes in line with Deci and Ryan's (2002) self-determination theory - specifically that sport engagement is more complex than just being based on self-efficacy alone. The findings from this study highlight that in order to increase sport engagement, opportunity to engage in sport must be improved and better advertised to children with disabilities in order to capitalise on the positive outcomes of the Paralympic games and other sporting mega-events.

Even though according to Wolff (2014) there is much less media representation and interest in the Paralympics, the research did find participants were positively engaged. The quotes reported in this study illustrate the inspiring and encouraging nature of the Paralympics for sport engagement amongst individuals, particularly children with disabilities. Literature by authors Fitzgerald (2005); Smith and Thomas (2006) and Thomas and Smith (2003) support this, noting a lack of opportunities for people with disabilities to engage in sport and physical activity.

This could also link to Deci and Ryan's (2002) concept of autonomy, and might explain why children had not taken up more sport. While the Paralympic Games appear to have had a positive effect on children; where opportunity lacks, motivation to participate in 


\section{AS ACCEPTED FOR PUBLICATION}

1 sport decreases. Equally it highlights the importance of multi-agency collaboration for

2 ensuring all children with disabilities are provided with safe and appropriate opportunities to

3 be included in physical activity based upon their individual needs.

4

5

\section{Limitations of the Study}

It is acknowledged this study had a limited sample and as such any results should be interpreted with caution. Nevertheless, this study highlights the usefulness of qualitative methods for exploring the perceptions of children with disabilities about the Paralympic Games. For example, children with disabilities were able to articulate, through discussion, how the Paralympics had impacted on their views and opinions of sport and physical activity. It is clear that this methodological approach has real potential to explore children with disabilities lived experiences of sport. Encouragingly, it was found that children were keen to take part in the study once they had consented and held pertinent views that contributed to understanding the legacy of the Games for children with disabilities. This indicates that further research should be done in order to generate discussion relating to the legacy for children with disabilities, with the aim of promoting social change in opportunities for children with disabilities to engage in sport. The study did, however, raise important methodological issues, which could be addressed in future research. Future studies should aim to recruit wider samples of children with disabilities so that their perceptions can also be accounted for. In this study, while children with physical and / or sensory difficulties were invited to participate, only children with physical disabilities opted to take part. As such, no data relating to the perceptions of children with other disabilities in relation to the Paralympic Games currently exists. It is worth noting, though, that many of the children who participated had associated intellectual disabilities and so it is important that we understand the spectrum 


\section{AS ACCEPTED FOR PUBLICATION}

1

of complex needs children with disabilities might have, and account for this when designing research so that the voices of these children are also heard.

The inclusion of diverse groups of children with disabilities does bring with it methodological difficulties, as some children are more able than others to communicate effectively verbally. This was evident in this study, where some children were less able to answer the interview questions leading to limitations in the data for some children. Coates and Vickerman (2013) note how qualitative data collection can be adapted to meet individual communication needs, and so future research should consider flexible and participatory research designs to account for the differing needs and abilities of participants.

\section{Conclusion}

This study in many ways supports the concept that there may be a legacy from the 2012 Paralympic Games. Specifically, it shows the positive role Paralympic athletes might play in improving children with disabilities’ perceptions of themselves. This all plays into self-determination theories (Deci \& Ryan 2002) through which if the right intrinsic and extrinsic factors can be established there is potential to enhance people with disabilities' engagement. It also highlights the potential role the Paralympics might play in changing perceptions of disability in the general public. However, further research is needed to draw concrete conclusions in relation to these factors.

Further studies should seek to generate discussion relating to the legacy for children with disabilities, with the aim of promoting social change in opportunities for children with disabilities to engage in sport. Alternative methods for generating data should be considered to ensure children's perceptions can be better understood, and researchers should consider the use of participatory methods (O’Kane, 2000). Studies such as that by Fitzgerald, Jobling and Kirk (2003) show participatory methods can be used effectively with children who have 


\section{AS ACCEPTED FOR PUBLICATION}

1 disabilities and this can empower children to raise issues important to them. The work of

2 Melanie Nind (e.g. Nind \& Vihna, 2013) is also a useful source of information for researchers

3 looking to carry out inclusive research with children who have disabilities, and this too should

4 be consulted by researchers aiming to carry out similar research.

Understanding the Paralympic legacy for children with disabilities can be complex for children with disabilities. This research has started to uncover some of the complexities. Yet, while this research may open up more questions than it answers, it provides a starting point for generating discussion about how these mega-events might contribute to changing children with disabilities perceptions of sport and otherwise.

\section{References}

Anderson, K. J., \& Cavallaro, D. (2002). Parents or pop culture? Children's heroes and role models. Childhood Education, 78(3), 161-168.

Armour, K., \& Dagkas, S. (2012). ‘Olympism’ and education: a critical review. Educational Review, 64(3), 261-264.

Bandura, A. (2002). Social foundations of thought and action. In Marks, D. F. (Ed.). The health psychology reader. Englewood Cliffs: Sage

Braun, V. \& Clarke, C. (2006). Using thematic analysis in psychology. Qualitative Research in Psychology, 3, 77-101.

Brittain, I. (2004a). Perceptions of disability and their impact upon involvement in sport for people with disabilities at all levels. Journal of Sport \& Social Issues. 28(4), 429-452.

Brittain, I. (2004b). The role of schools in constructing self-perceptions of sport and physical education in relation to people with disabilities. Sport, Education and Society. 9(1), 75-94.

Broderick, C. (2013). Children, sport and the Olympics: Observations from the Games of the XXX Olympiad in London. Journal of Paediatrics and Child Health. 49(9), 701-703 


\section{AS ACCEPTED FOR PUBLICATION}

1 Cavill, N. \& Bauman, A. (2004). Changing the way people think about health-enhancing physical activity: do mass media campaigns have a role? Journal of Sports Sciences, 22(8), 771-790.

Chatziefstathiou, D. (2012). Olympic education and beyond: Olympism and value legacies from the Olympic and Paralympic Games. Educational Review, 64 (3), 385-400.

Centre for Sport, Physical Education and Activity Research (2012), Measuring an Olympic and Paralympic Effect on Sport Participation, Canterbury Christ Church University, Canterbury

Coates, J. (2011). Teaching inclusively: are secondary physical education teachers sufficiently prepared to teach in inclusive environments? Physical Education and Sport Pedagogy. 17 (4), 349-365

Coates, J. \& Vickerman, P. (2013) A review of methodological strategies for consulting children with special educational needs in physical education, European Journal of Special Needs Education, available online, DOI:10.1080/08856257.2013.797705

Cresswell, J. (2007). Qualitative Inquiry and Research Design, Choosing Among five Traditions, (2 ${ }^{\text {nd }}$ Eds), Sage, California

Deci, E. L., \& Ryan, R. M. (Eds.). (2002). Handbook of Self-Determination Research. NY: University Rochester Press

Dickson, T. J., Benson, A. M., \& Blackman, D. A. (2011). Developing a framework for evaluating Olympic and Paralympic legacies. Journal of Sport \& Tourism, 16(4), 285302.

DiLorenzo, T. M., Stucky-Ropp, R. C., Vander Wal, J. S., \& Gotham, H. J. (1998). Determinants of exercise among children. II. A longitudinal analysis. Preventive Medicine, 27(3), 470-477.

Feltz, D. (1992). Understanding motivation in sport: a self-efficacy perspective. In Roberts, G. C. (1992). Motivation in Sport and Exercise. IL: Human Kinetics Books

Ferrara, K., Burns, J. and Mills, H. (2015) Public attitudes toward people with intellectual disabilities after viewing Olympic or Paralympic performance. Adapted Physical Activity Quarterly, 32 (1). pp. 19-33 


\section{AS ACCEPTED FOR PUBLICATION}

1 Fitch, K. (2012). Proscribed drugs at the Olympic Games: permitted use and misuse (doping) by athletes. Clinical Medicine, 12(3), 257-260.

Fitzgerald, H. (2005). Still Feeling Like a Spare Piece of Luggage? Embodied Experiences of (Dis)Ability in Physical Education and School Sport. Physical Education and Sport Pedagogy, 10(1), 41 - 59.

Fitzgerald, H. (2012) 'The Paralympics and knowing disability', International Journal of Disability, Development and Education 59 (3): 243-255.

Fitzgerald, H., Jobling, A. \& Kirk, D. (2003). Listening to the 'voices' of students with severe learning difficulties through a task-based approach to research and learning in physical education. Support for Learning. 18, 123-129.

Goggin, G. \& Newell, C. (2000). Crippling Paralympics? Media, Disability and Olympism . Media International Australia, Incorporating Culture \& Policy. 97, 71-83.

Gold, J. R., \& Gold, M. M. (2007). Access for all: the rise of the Paralympic Games. The Journal of the Royal Society for the Promotion of Health, 127(3), 133-141.

Goodwin, D. \& Watkinson, J. (2000). Inclusive Physical Education from the Perspectives of Students with Physical Disabilities. Adapted Physical Activity Quarterly, 17, 144-160.

Greig, D. A., August, O., \& Race, W. (2006). Establishing a new reality for Paralympic sport: An examination of the Torontolympiad and its legacy on the Canadian disabled sport system and the Paralympic Movement. Proceedings of the North American Society for Sport History, 33-34.

Hardin, B. Hardin, M., Lynn, S., \& Walsdorf, K. (2001). Missing in action? Images of disability in Sports Illustrated for Kids. Disability Studies Quarterly, 21(2).

Hollings, S. C., Hopkins, W. G., \& Hume, P. A. (2012). Environmental and venue-related factors affecting the performance of elite male track athletes. European Journal of Sport Science, 12(3), 201-206.

Jobling, A. (2012). The Paralympic Games. International Journal of Disability, Development and Education, 59(3), 225-229.

Kama, A. (2004), Supercrip Versus Pitiful Handicapped: Reception of Disabling Images by Disabled Audience Members, Communications, 29(4), 447-466. 


\section{AS ACCEPTED FOR PUBLICATION}

1 Lenskyj, H. J. (2012). Olympic education and Olympism: still colonizing children's minds. Educational Review, 64(3), 265-274.

Lockwood, P. \& Kunda, Z. (1997). Superstars and me: Predicting the impact of role models on the self. Journal of personality and social psychology, 73(1), 91.

Lockwood, P., \& Kunda, Z. (1999). Increasing the salience of one's best selves can undermine inspiration by outstanding role models. Journal of personality and social psychology, 76(2), 214.

Lockwood, P., Sadler, P., Fyman, K., \& Tuck, S. (2004). To do or not to do: Using positive and negative role models to harness motivation. Social Cognition. 22(4), 422-450.

Lyons, E. and Coyle, A. (2007). Analysing Qualitative Data in Psychology. London: Sage

Kippelen, P., Fitch, K. D., Anderson, S. D., Bougault, V., Boulet, L. P., Rundell, K. W., ... \& McKenzie, D. C. (2012). Respiratory health of elite athletes-preventing airway injury: a critical review. British journal of sports medicine, 46(7), 471-476.

Misener, L., Darcy, S., Legg, D. \& Gilbert, K. (2013). Beyond Olympic Legacy: Understanding Paralympic Legacy through a Thematic Analysis. Journal of Sport Management, 27, 329-341.

Nind, M., Flewitt, R., \& Pavler, J. (2010), The Social Experience of Early Childhood for Children with Learning Disabilities: Inclusion, Competence and Agency, British Journal of Sociology of Education, 36(6), 653-670

Nind, M. \& Vinha, H. (2013). Doing research inclusively: bridges to multiple possibilities in inclusive research. British Journal of Learning Disabilities, i1-i8, doi:10.1111/bld.12013.

O’Kane, C. (2000). The development of participatory techniques: Facilitating children's views about decisions which affect them. In Christensen P. \& James A. Research with Children: Perspectives and Practices. London: Falmer Press.

Panagiotou, A. K., Evaggelinou, C., Doulkeridou, A., Mouratidou, K., \& Koidou, E. (2011). Attitudes of 5th and 6th grade Greek students toward the inclusion of children with disabilities in physical education classes after a Paralympic education program. European Journal of Adapted Physical Activity, 1(2).

Pappous, A.; Marcellini, A., and de Léséleuc, E. (2011). Contested Issues in Research on the 


\section{AS ACCEPTED FOR PUBLICATION}

Media Coverage of Female Paralympic Athletes. Sport in Society: Cultures, Commerce, Media, Politics, 14 (9), 1182-1191.

Purdue, D. \& Howe, P.D. (2012). Empower, inspire, achieve: (dis)empowerment and the Paralympic Games, Disability \& Society, 27:7, 903-916.

Shakespeare, T. (1999) Art and lies? Representations of disability on film. In: Corker, M. and French, S. (eds.) Disability Discourse. Buckingham: Open University Press. 164-172

Shibli, S., Gratton, C., \& Bingham, J. (2012). A forecast of the performance of Great Britain and Northern Ireland in the London 2012 Olympic Games. Managing Leisure, 17(23), 274-290.

Smith, A. \& Thomas, N. (2006). Including pupils with special educational needs and disabilities in national curriculum physical education: A brief review. European Journal of Special Needs Education. 21: 69-83.

Sport \& Recreation Alliance. (2012). Olympic and Paralympic Legacy Survey. London: Sport and Recreation Alliance.

Sport England. (2001). Disability Survey 2000. Young People with a Disability and Sport. Headline Findings, London: Sport England.

Sport England. (2015). Once a week participation in sport, available from https://www.sportengland.org/media/913623/aps9q2headlines.pdf, last accessed $15 / 09 / 2015$

Titchkosky, T. (2007). Reading and Writing Disability Differently: The Textured Life of Embodiment, London: University of Toronto.

Thomas, N., \& Smith, A. (2003). Preoccupied With Able-Bodiedness? An Analysis of the British Media Coverage of the 2000 Paralympics Games. Adapted Physical Activity Quarterly, 20(2), 166.

UK Government \& Mayor of London. (2013). Inspired by 2012: The legacy from the London 2012 Olympic and Paralympic Games. London: Cabinet Office 


\section{AS ACCEPTED FOR PUBLICATION}

1 Vescio, J., Wilde, K., \& Crosswhite, J. J. (2005). Profiling sport role models to enhance

2

3

4

5

6

7

8

9

10

11

12

13 initiatives for adolescent girls in physical education and sport. European Physical Education Review, 11(2), 153-170.

Weed, M., Coren, E., Fiore, J., Wellard, I., Mansfield, L., Chatziefstathiou, D., \& Dowse, S. (2012). Developing a physical activity legacy from the London 2012 Olympic and Paralympic Games: a policy-led systematic review. Perspectives in public health, 132(2), 75-80.

Wolff, E. 2014, Disabled Athlete, Advocate Eli Wolff on the Overlooked Dynamism \& Diversity of the Paralympic Games, Democracy Now, accessed at: http://www.democracynow.org/2012/9/10/disabled_athlete_advocate_eli_wolff_on 


\section{Table 1: Interview schedule}

\section{Interview Schedule - Paralympic Legacy}

1. I want to talk to you about the Paralympic Games. Can you tell me what you know about the Paralympic Games?

- Prompts - Who takes part? What sports do they play in the Paralympic Games? When is the Paralympic Games? Where do you find out information about the Paralympic Games? What do you know about the Olympic Games?

- All children reminded: “The Paralympic Games are the same as the Olympic Games but they are for athletes who have some trouble with moving, like being in a wheel chair or not having full use of their arms; trouble seeing properly or hearing; or who have other difficulties which mean they cannot compete in the Olympics.” Video of Paralympic sports shown.

2. What do you think about the Paralympic Games?

- Prompts - What do you feel about the athletes in the videos? How does watching the athletes make you feel? What do think about the Paralympic Games compared with the Olympic Games?

3. What do you think about sport?

- Prompts - Do you take part in sport (in or out of school)? What sports do you take part in? What do you think about those sports?

4. What do you think about sport for people who have disabilities?

5. Do you think there is enough opportunity for people who have disabilities to take part in sport? Why?

6. Thinking about the Paralympic Games, do you think they encourage children with disabilities to take part in sport? Why?

7. Has the Paralympic Games changes how you think about the sport you take part in / encouraged you to do more sport? Why? 
AS ACCEPTED FOR PUBLICATION

Table 2: Participant Information

\begin{tabular}{|c|c|c|c|c|c|}
\hline School & Participant & Age & Sex & Disability & Participation in sport \\
\hline \multirow[t]{3}{*}{ Special } & Gareth & 15 & $\begin{array}{l}\text { Male } \\
\text { (M) }\end{array}$ & Cerebral Palsy & $\begin{array}{l}\text { School PE and ad hoc Arts } \\
\text { Plus (extracurricular) sports } \\
\text { activities }\end{array}$ \\
\hline & Chris & 16 & M & Cerebral Palsy & School PE \\
\hline & Warren & 16 & $\mathrm{M}$ & Cerebral Palsy & $\begin{array}{l}\text { School PE and Whizz Kids } \\
\text { (extracurricular disability } \\
\text { sport club during school } \\
\text { holidays) }\end{array}$ \\
\hline \multirow[t]{5}{*}{ Mainstream } & Cassie & 14 & $\begin{array}{l}\text { Female } \\
\text { (F) }\end{array}$ & $\begin{array}{l}\text { Developmental Co- } \\
\text { ordination Disorder }\end{array}$ & $\begin{array}{l}\text { School PE and national } \\
\text { school athletics competitor. }\end{array}$ \\
\hline & Zara & 16 & $\mathrm{~F}$ & Skeletal Dysplasia & School PE \\
\hline & Georgina & 16 & $\mathrm{~F}$ & $\begin{array}{l}\text { Awaiting heart and } \\
\text { lung transplant }\end{array}$ & $\begin{array}{l}\text { No participation in sport for } \\
\text { health reasons }\end{array}$ \\
\hline & David & 12 & M & Cerebral Palsy & School PE \\
\hline & Simon & 12 & M & Friedrich’s Ataxia & School PE \\
\hline
\end{tabular}

